\title{
In vitro study on the contribution of the rat intestine-pancreas to glucose homeostasis
}

\author{
M. A. Tormo, M. A. G.Zubeldia, J. L. Montero and J. E. Campillo \\ Department of Physiology, Faculty of Medicine, University of Extremadura, Badajoz, Spain
}

\begin{abstract}
Summary. Insulin release, glucose utilisation and lactate production were investigated using an in vitro perfused rat intestine-pancreas preparation after intraluminal or arterial glucose administration. In the absence of intraluminal glucose administration, both glucose utilisation and lactate production seem to be dependent on the arterial glucose concentration. Despite the different proportions in the portal values of glucose and lactate found at the various arterial glucose concentrations, the percentage of the total carbon atoms from infused glucose recovered in the portal vein remained constant. A significant $(p<0.01)$ increase in insulin secretion was observed when the arterial glucose concentration was increased from 5.5 to $16.7 \mathrm{mmol} / 1$. After intraluminal administration of glucose ( $4 \mathrm{~g} / \mathrm{kg}$ body weight) both as a bolus or as an infusion, the lactate produced and the insulin released by the preparation were not significantly increased
\end{abstract}

with respect to values measured in the absence of intraluminal glucose load. After intraluminal administration of glucose $(1 \mathrm{~g} / \mathrm{kg}$ body weight $)$ as a bolus, the net translocation of glucose from the lumen to the vascular circuit was apparently reduced when the glucose concentration was increased in the perfusate from 2.75 to $11.0 \mathrm{mmol} / \mathrm{s}$; this reduction could be dependent on an increase in the metabolism of absorbed glucose. In conclusion, the functional unit intestine-pancreas seems to play an important role in glucose homeostasis by elaborating the adequate mixture of glucose and lactate that must reach the liver under the various metabolic conditions.

Key words: Perfused intestine-pancreas, glucose utilisation lactate production, insulin release.
Although it is well established that the intestine shows a high glycolytic activity, its contribution to the regulation of plasma glucose levels has not been elucidated. Of the various cell types that constitute the intestine, the epithelial cells and the smooth muscle seem to exhibit the highest glycolytic activity - lactate being the dominant product of glucose metabolism [1-13]. Glucose can be supplied to these intestinal cells by two different routes, from the lumen and from the blood. The first route is clearly open only when carbohydrate digestion and absorption occur; the second route is always available. Through the luminal route, the highly polarised epithelial cells must absorb glucose from the lumen and pass it to the smooth muscle. Through the vascular route, glucose reaches both cell types directly [1]. It has been reported that the metabolic fate of glucose and the proportion of metabolised glucose converted into lactate could not be the same when presented alternatively from both routes $[2,3,5,7,8]$. Furthermore, the total amount of glucose metabolised and the proportion of the glucose transformed into lactate could be dependent on the glucose concentrations that are present simultaneously at the luminal and the vascular side of the intestine. This highly polarised metabolic capacity of the intestine suggests that the intestine may play an important role in glucose homeostasis.

Intestine and the endocrine pancreas must be considered as a single functional unit [14] that is located strategically before the liver. In addition to their well known endocrine secretory activity, one of the physiological functions of the intestine-pancreas unit could be to elaborate the maximal effective mixture of glucose and lactate that reach the liver under various metabolic conditions.

In order to investigate such a possibility, we have used an in vitro preparation consisting of the rat small intestine-pancreas, having intact arterial supply and venous drainage, perfused through the physiological vascular route without recycling of the perfusate and allowing intraluminal administration of glucose. In the present work, we report the data obtained on glucose 


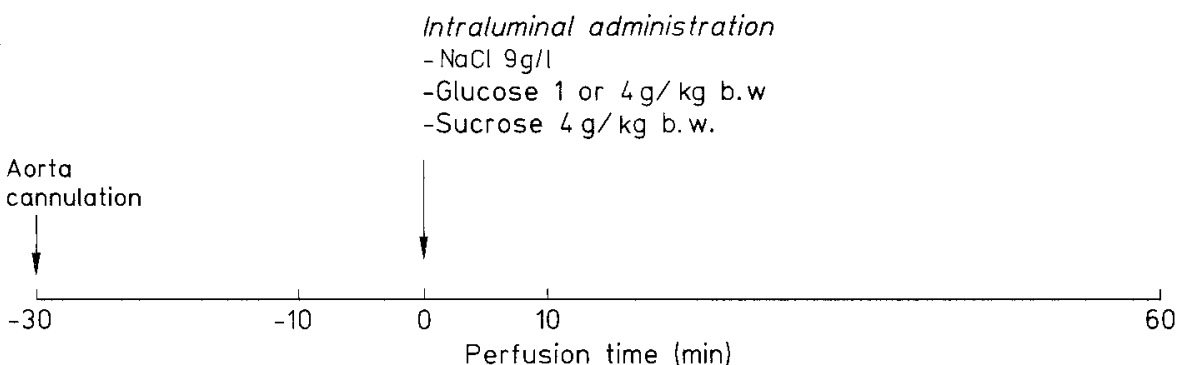

Perfusate glucose concentration (mmol/l) $2.75,5.5$ or 11.0
5.5

16.7
Fig. 1. Diagram of the experimental protocols used utilisation, lactate production and insulin secretion by this preparation, after arterial or luminal administration of glucose and in the presence of various arterial glucose concentrations.

\section{Materials and methods}

Male Wistar rats were maintained on a standard diet (Sanders, Sevilla, Spain) with free access to water and housed in a room at $24^{\circ} \pm 2^{\circ} \mathrm{C}$ with lighting from 08.00 to 20.00 hours. The isolation and perfusion of the small intestine-pancreas was performed according to Levine et al. [15] and Campillo et al. [16] with minor modifications. Fed rats $(250 \mathrm{~g})$ were anaesthetised with intraperitoneal sodium pentobarbital $(60 \mathrm{mg} / \mathrm{kg}$ body weight, Nembutal, Serva, Heidelberg, FRG), and the abdomen was opened. The colon was removed and the inferior mesenteric artery was ligated. The oesophagus was ligated and transected about $0.5 \mathrm{~cm}$ above the gastroesophagea junction. The spleen and stomach together with the gastric and pancreatic fat pad were removed. Ligation and transection of all abdominal branches of the aorta, except for the superior mesenteric and the celiac arteries, and all branches of the inferior vena cava were then performed, and the aorta was ligated. Then the thorax was opened and a silver cannula, connected to the perfusion system, was quickly placed inside the aorta just below the diaphragm and tied. The oxygenated perfusion fluid was immediately allowed to enter the preparation. The hepatic artery was ligated and a silver cannula was placed inside the portal vein and tied. The liver was removed, the lumen of the small bowel was flushed free of food residue with $10 \mathrm{ml}$ of $\mathrm{NaCl} 9 \mathrm{~g} / 1$ at $37^{\circ} \mathrm{C}$ and then the small bowel end was tied at the ileocecal sphincter level. A polyethylene cannula was inserted inside the duodenum and tied. The entire preparation was then removed and placed in a small thermostatised $\left(37^{\circ} \mathrm{C}\right)$ bath containing $\mathrm{NaCl} 9 \mathrm{~g} / 1$ supplemented with $2 \mathrm{mg} / 100 \mathrm{ml}$ dextran (M.W. 70000, Sigma, St.Louis, Mo, USA). The isolated preparation was perfused via the cannulated aorta without recirculation with a Krebs-Henseleit bicarbonate medium $\left(37^{\circ} \mathrm{C}\right)$ containing $(\mathrm{mmol} / \mathrm{l}): \mathrm{NaCl} 120, \mathrm{MgO}_{4}$ 0.7, $\mathrm{NaHCO}_{3}$ $25, \mathrm{CaCl}_{2} 1$, and $\mathrm{KH}_{2} \mathrm{PO}_{4} 1.2$, glucose $2.75,5.5,11.0$ or 16.7 and supplemented with $0.5 \mathrm{mg} / 100 \mathrm{ml}$ albumin (bovine albumin, Sigma) and $1.5 \mathrm{mg} / 100 \mathrm{ml}$ dextran. The perfusion medium was oxygenated with $95 \% \mathrm{O}_{2} \pm 5 \% \mathrm{CO}_{2}$ for 30 min prior to attachment of the preparation and throughout the experiment, the $\mathrm{pH}$ was kept constant at 7.4. The perfusate was circulated using a peristaltic pump (Harvard, model 12034) at a flow rate of $3 \mathrm{ml} / \mathrm{min}$ resulting in an arterial perfusion pressure of $20-30 \mathrm{~mm} \mathrm{Hg}$. After a stabilisation period of $20 \mathrm{~min}$ without specimen collection, the samples were collected in chilled tubes from the cannulated portal vein at the times indicated in the results. The following diagram summarises the experimental protocols used (Fig. 1).

At the end of the experiments, the intestine was removed and the content collected and analysed for glucose and lactate. For insulin measurements, aliquots of the samples were transferred to chilled tubes and stored at $-70^{\circ} \mathrm{C}$ until assayed. Immunoreactive Insulin (IRI) was assayed by radioimmunoassay (Amershan, Buckinghamshire, UK) using rat insulin (Novo, Copenhagen, Denmark) as standard. Lactate and glucose $[16,18]$ were assayed enzymatically, using reagents from Boehringer-Mannheim (Mannheim, FRG). $\mathrm{PO}_{2}$, $\mathrm{PCO}_{2}$ and $\mathrm{pH}$ were measured in the in-and outflow of the perfusate with a gas analyzer (ABL 330 Radiometer, Copenhagen, Denmark). The samples were aspirated as anaerobically as possible with an arterial blood sampler (Preza-pak II, Terumo Corporation, Tokyo, Japan). The oxygen supply to the preparation was adequate to support rates of aerobic respiration.

The levels of lactate, glucose and IRI in the portal vein were expressed as $\mu \mathrm{mol}$ or ng per min calculated by multiplying their concentration measured in the samples by the flow rate. The total values of lactate produced and glucose recovered in portal vein during the $60 \mathrm{~min}$ experimental period (mmol/60 min) were calculated by planimetry of the profiles of lactate and glucose portal levels recorded for each individual perfusion. The total amount of glucose infused during the $60 \mathrm{~min}$ experimental period was calculated by multiplying the glucose concentration in the perfusate, by the total volume of perfusion medium utilised (flow rate $\times 60 \mathrm{~min}$ ). The total amount of glucose consumed by the preparation $(\mathrm{mmol} / 60 \mathrm{~min})$ was obtained by calculating the difference between the total glucose supplied to the preparation and the total glucose recovered in portal vein. The proportion of both infused or consumed glucose that account for the lactate produced was obtained by the expression: lactate released $\times 0.5 /$ glucose infused or consumed $\times 100$. The overbasal increment in portal glucose values ( $\mu \mathrm{mol} / \mathrm{min}$ ) were calculated by subtracting the mean values of portal glucose measured at the equilibration period to each values measured during the experimental period. The total over-basal increment in portal glucose ( $\mathrm{mmol} / 60 \mathrm{~min}$ ) was calculated by planimetry of the resulting overbasal individual profiles. The total luminal glucose absorbed by the preparation (mmol/60 min) was calculated from the difference between the total glucose given intraluminally and the glucose remaining in the intestinal lumen at the end of the experiment.

The preparation maintained a good viability through the experiments, showing a moderate intestinal motility; the morphology and histology of the preparation were well conserved.

\section{Statistical analysis}

All results are expressed as mean \pm SEM; statistical evaluation was performed by using the non-paired Student's $t$-test. 


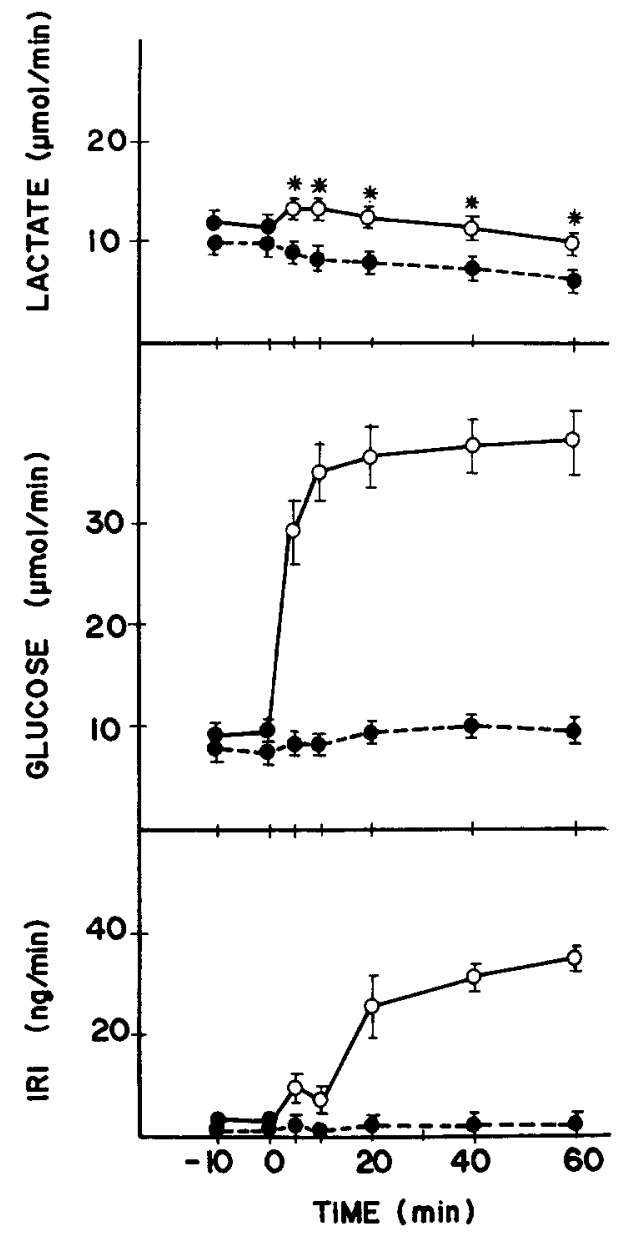

Fig. 2. Portal levels of lactate, glucose and immunoreactive insulin (IRI) measured when intestine-pancreas preparations were perfused at $5.5(0)$ and $16.7 \mathrm{mmol} / 1(0)$ glucose in the perfusate. Number of perfusions is $n=9(O)$ and $n=7(0)$ for glucose and lactate $n=4(O)$ and $n=3(0)$ for IRI. * correspond to $p<0.01$

Table 1. Effect of arterial glucose concentration on the metabolism of arterially supplied glucose; $n=$ number of perfusions

\begin{tabular}{|c|c|c|c|c|c|}
\hline & \multicolumn{5}{|c|}{ Arterial glucose $(\mathrm{mmol} / \mathrm{l})$} \\
\hline & 2.75 & 5.5 & & 11.0 & \\
\hline $\begin{array}{l}\text { Glucose infused } \\
\text { (mmol/60 min) }\end{array}$ & $\begin{array}{c}0.53 \\
(n=3)\end{array} \pm 0.014$ & $\begin{array}{c}0.96 \\
(n=8)\end{array}$ & \pm 0.05 & $\begin{array}{c}2.09 \\
(n=4)\end{array}$ & \pm 0.054 \\
\hline $\begin{array}{l}\text { Portal glucose } \\
\qquad(\mathrm{mmol} / 60 \mathrm{~min})\end{array}$ & $\underset{(n=3)}{0.28} \pm 0.019$ & $\begin{array}{c}0.56 \\
(n=8)\end{array}$ & \pm 0.052 & $\begin{array}{c}1.47 \\
(n=4)\end{array}$ & \pm 0.088 \\
\hline $\begin{array}{l}\text { Percent of infused } \\
\text { glucose }\end{array}$ & $53.3 \pm 2.70$ & 57.76 & \pm 3.10 & 70.8 & \pm 4.60 \\
\hline $\begin{array}{l}\text { Glucose consumed } \\
\text { (mmol/60 min) }\end{array}$ & $\underset{(n=3)}{0.25} \pm 0.032$ & $\begin{array}{c}0.40 \\
(n=8)\end{array}$ & \pm 0.02 & $\begin{array}{c}0.63 \\
(n=4)\end{array}$ & $\pm 0.10^{\mathrm{a}}$ \\
\hline $\begin{array}{l}\text { Percent of infused } \\
\text { glucose }\end{array}$ & $46.7 \pm 2.7$ & 42.2 & \pm 3.1 & 28.7 & $\pm 4.6^{\mathrm{a}}$ \\
\hline $\begin{array}{l}\text { Portal lactate } \\
\quad(\mathrm{mmol} / 60 \mathrm{~min})\end{array}$ & $\underset{(n=3)}{0.33} \pm 0.023$ & $\begin{array}{c}0.47 \\
(n=5)\end{array}$ & \pm 0.03 & $\begin{array}{c}0.76 \\
(n=3)\end{array}$ & $\pm 0.05^{b}$ \\
\hline $\begin{array}{l}\text { Percent of infused } \\
\text { glucose }\end{array}$ & $31.5 \pm 1.8$ & 24.5 & \pm 1.9 & 17.9 & $\pm 1.3^{\mathrm{a}}$ \\
\hline $\begin{array}{l}\text { Percent of } \\
\text { consumed glucose }\end{array}$ & $69.7 \quad \pm 11.5$ & 59.2 & \pm 4.5 & 66.9 & \pm 11.9 \\
\hline
\end{tabular}

$\bar{a} p<0.05 ;{ }^{b} p<0.01$ versus values obtained at $2.75 \mathrm{mmol} / \mathrm{l}$ arterial glucose

\section{Results}

\author{
Effect of an acute increase in arterial glucose \\ concentration on lactate production \\ and insulin secretion
}

As shown in Figure 2, in preparations perfused in the presence of glucose $5.5 \mathrm{mmol} / 1$ in the perfusate, portal glucose levels increased slightly and portal lactate levels showed a light reduction through the experiment. Portal IRI levels were low and constant during the whole experiment. When the arterial glucose concentration was acutely raised at time 0 from 5.5 to $16.7 \mathrm{mmol} / 1$, the portal glucose levels increased acutely to levels around $30-40 \mu \mathrm{mol} / \mathrm{min}$ and the portal lactate levels were significantly increased $(p<0.01)$ versus that recorded under $5.5 \mathrm{mmol} / 1$ arterial glucose. Portal IRI levels increased significantly $(p<0.01)$ after the increase in arterial glucose concentration.

\section{Effect of the arterial glucose concentration on the glucose metabolism and lactate production}

As shown in Table 1 , the absolute values ( $\mathrm{mmol} / 60 \mathrm{~min}$ ) of glucose consumed by the preparation increased when the glucose concentration increased in the perfusate. When the glucose consumed was expressed as a percentage of the total glucose infused during the experimental period, the proportion of glucose infused that was utilized by the preparation was significantly $p<0.05$ ) reduced at $11.0 \mathrm{mmol} / 1$ arterial glucose versus values obtained at 2.75 and $5.5 \mathrm{mmol} / 1$ glucose. The appearance of glucose in the lumen $(\mathrm{mmol} / 60 \mathrm{~min})$ was $0.006 \pm 0.0039$ at 2.75 , $0.0091 \pm 0.006$ at 5.5 and $0.0086 \pm 0.009$ at $11.0 \mathrm{mmol} / 1$ glucose. The absolute values of lactate $(\mathrm{mmol} / 60 \mathrm{~min})$ measured in portal vein increased when the glucose concentration increased in the perfusate. The proportion of the total glucose infused during the experimental period that accounts for the lactate produced by the preparations was reduced when the glucose concentration was increased in the perfusate - this reduction being statistically significant $(p<0.01)$ at $11.0 \mathrm{mmol} / 1$ glucose versus values obtained at $2.75 \mathrm{mmol} / 1$ glucose. The proportion of the consumed glucose that accounts for the lactate released by the preparation to the vascular circuit was similar at the three arterial concentrations of glucose. The appearance of lactate in the lumen (mmol $/ 60 \mathrm{~min})$ was $0.024 \pm 0.0005$ at 2.75 , $0.043 \pm 0.027$ at 5.5 and $0.052 \pm 0.017$ at $11.0 \mathrm{mmol} / 1$ arterial glucose.

\section{Effect of intraluminal glucose administration on lactate production and insulin secretion}

Figure 3 shows the portal values of lactate, glucose and IRI measured when the preparations were per- 


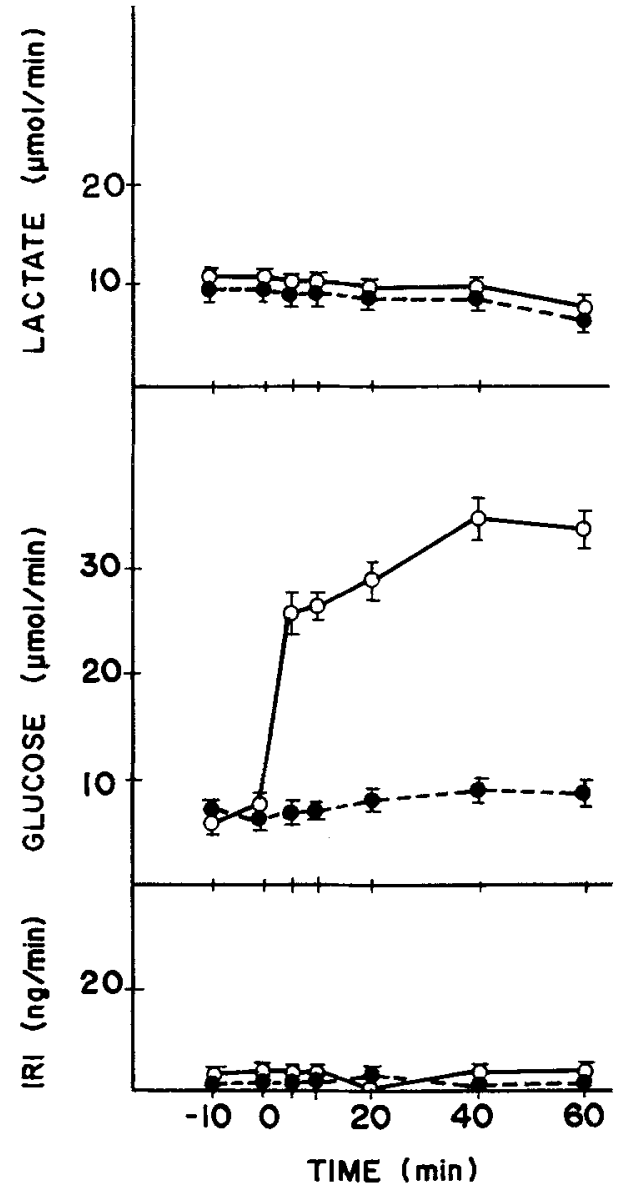

Fig.3. Portal levels of lactate, glucose and immunoreactive insulin (IRI) measured when intestine-pancreas preparations were perfused at $5.5 \mathrm{mmol} / \mathrm{l}$ glucose from the beginning $(\mathrm{min}-30)$ and during the whole experiment, and, at time 0 , they received as a bolus ( $1 \mathrm{~min}$ ) $1.5 \mathrm{ml}$ of $\mathrm{NaCl} 9 \mathrm{~g} / 1$ alone $(\Theta)$ or containing glucose $(4 \mathrm{~g} / \mathrm{kg}$ body weight) (O). Number of perfusions is $n=15)(0)$ and $n=5(0)$ for glucose and lactate; $n=3(\odot)$ and $n=3(O)$ for IRI

fused with $5.5 \mathrm{mmol} / 1$ arterial glucose in the perfusate; and, at the time 0 , they received intraduodenally as a bolus ( $1 \mathrm{~min}) 1.5 \mathrm{ml}$ of $\mathrm{NaCl} 9 \mathrm{~g} / 1$ alone or containing glucose ( $4 \mathrm{~g} / \mathrm{kg}$ body weight).

In perfusions with intraluminal administration of $\mathrm{NaCl} 9 \mathrm{~g} / 1$ alone, portal levels of glucose, lactate and IRI were identical to those recorded in perfusions with $5.5 \mathrm{mmol} / 1$ arterial glucose and without intraluminal administration of $\mathrm{NaCl} 9 \mathrm{~g} / \mathrm{l}$. After the intraluminal administration of glucose, a rapid increase in portal glucose levels was observed; portal levels and IRI were identical to those recorded after $\mathrm{NaCl}$ administration. Similar results to those shown in Figure 3 were observed when both $\mathrm{NaCl} 9 \mathrm{~g} / 1$ and glucose $(4 \mathrm{~g} / \mathrm{kg}$ body weight) were administered intraluminally as an infusion ( $20 \mathrm{~min}$ ). After intraluminal administration as a bolus of sucrose $(4 \mathrm{~g} / \mathrm{kg}$ body weight), the portal glucose levels increased throughout the experimental period and the lactate measured in porta was $0.76 \pm 0.09 \mathrm{mmol} / 60 \mathrm{~min}$. The appearance of lactate

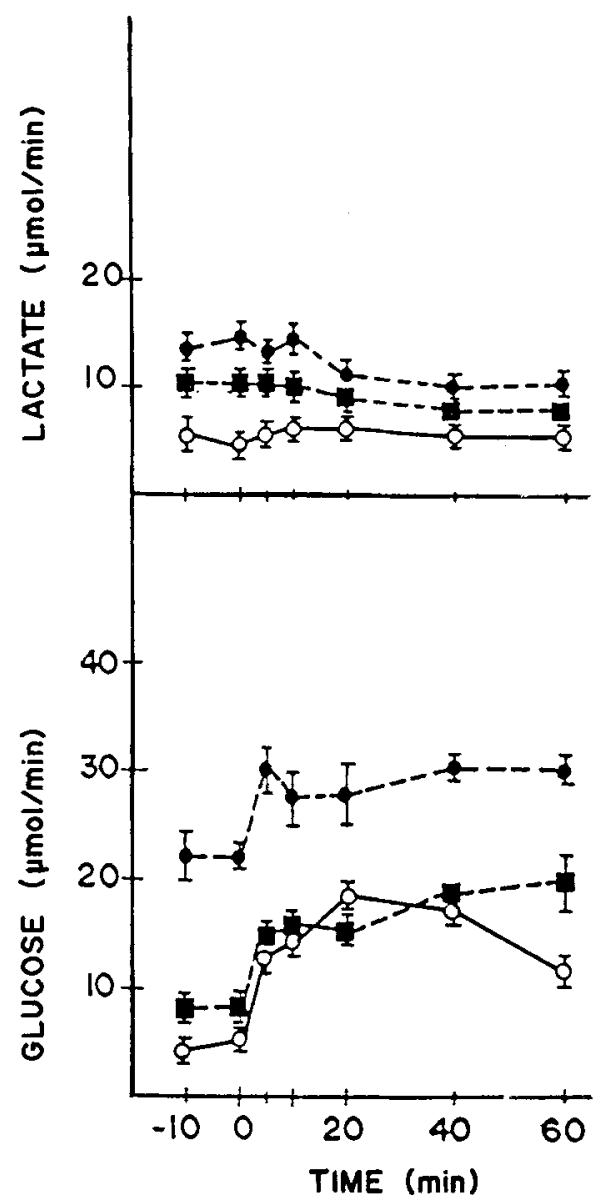

Fig.4. Portal values of lactate and glucose measured when intestine-pancreas preparations were perfused at $2.75(\mathrm{O}, n=3), 5.5(\mathbf{\square}$, $n=3)$ or $11.0(, n=3) \mathrm{mmol} / 1$ arterial glucose from the beginning $(\min -30)$ and during the whole experiment, and, at time 0 , they received as a bolus $(1 \mathrm{~min}) 1.5 \mathrm{ml}$ of $\mathrm{NaCl} 9 \mathrm{~g} / \mathrm{l}$ containing glucose $(1 \mathrm{~g} / \mathrm{kg}$ body weight $)$

and glucose in the lumen after sucrose administration was: $0.104 \pm 0.004 \mathrm{mmol} / 60 \mathrm{~min}$ and $0.31 \pm 0.08$ $\mathrm{mmol} / 60 \mathrm{~min}$ respectively.

\section{Effect of arterial glucose concentration of the glucose absorption, glucose metabolism and lactate production}

As shown in Figure 4 after intraluminal glucose administration ( $1 \mathrm{~g} / \mathrm{kg}$ body weight), a clear increase in portal glucose levels was observed under all experimental conditions. Portal lactate values showed a slight and progressive reduction through the experiment. The total lactate values measured in porta (mmol/60 $\mathrm{min}$ ) after glucose load were $0.36 \pm 0.055$ at $2.75,0.55 \pm 0.053$ at 5.5 and $0.72 \pm 0.038$ at $11.0 \mathrm{mmol} / 1$ arterial glucose. Only at 2.75 and $5.5 \mathrm{mmol} / 1$ glucose, a small increase in portal lactate levels was observed versus values obtained under the corresponding basal ( $\mathrm{NaCl} 9 \mathrm{~g} / 1$ alone) condition. As 
Table 2. Effect of arterial glucose concentration on the absorption and net translocation of intraluminal glucose and luminal lactate production after intraduodenal administration of glucose $(1 \mathrm{~g} / \mathrm{kg}$ body weight). Number of experiments as shown in Figure 4

\begin{tabular}{lccc}
\hline & \multicolumn{3}{c}{ Arterial glucose $(\mathrm{mmol} / \mathrm{l})$} \\
\cline { 2 - 5 } & 2.75 & 5.5 & 11.0 \\
\hline $\begin{array}{c}\text { Glucose absorbed } \\
\text { (mmol/60 min) }\end{array}$ & $1.21 \pm 0.04$ & $1.25 \pm 0.22$ & $1.08 \pm 0.12$ \\
$\begin{array}{c}\text { Percent of total } \\
\text { glucose load }\end{array}$ & $76.6 \pm 2.5$ & $71.6 \pm 4.9$ & $62.2 \pm 5.0$ \\
$\begin{array}{c}\text { Over basal portal } \\
\text { Glucose } \\
\text { (mmol/60 min) }\end{array}$ & $0.65 \pm 0.013$ & $0.57 \pm 0.045$ & $0.44 \pm 0.057$ \\
$\begin{array}{c}\text { Percent of } \\
\text { absorbed glucose }\end{array}$ & $53.4 \pm 2.2$ & $49.3 \pm 10.6$ & $42.2 \pm 8.2$ \\
$\begin{array}{c}\text { Luminal lactate } \\
\text { (mmol/60 min) }\end{array}$ & $0.048 \pm 0.015$ & $0.046 \pm 0.012$ & $0.052 \pm 0.04$ \\
\hline
\end{tabular}

suggested from the data shown in Figure 4 after the intraluminal administration of glucose, the over-basal increase in portal glucose levels was apparently reduced by increasing the arterial glucose concentration.

This phenomenon is clearly shown in Table 2 where the portal glucose levels measured after the intraluminal glucose load were expressed as increments over portal glucose levels recorded at equilibration period. As shown in Table 2, the percentage of the absorbed glucose that accounts for the net translocation of glucose to the vascular circuit (over basal portal glucose) was clearly reduced by increasing the arterial concentration of glucose. The glucose absorbed by the intestine after intraluminal administration of glucose $(1 \mathrm{~g} / \mathrm{kg}$ body weight), both in absolute terms and in percentage of the total glucose load, was only slightly reduced by increasing the arterial glucose concentration. The appearance of lactate in the lumen after glucose load was low and identical at the three arterial glucose concentrations.

\section{Discussion}

\section{Metabolism of arterially supplied glucose}

Our results show that in the absence of intraluminal glucose administration; the perfused preparation consumed a high proportion of the arterially supplied glucose and released lactate to the vascular circuit. These data are in agreement with those reported using in vitro $[1-3,5,6,8]$ or in vivo $[7,11,13]$ experiments. Under the present experimental conditions, both glucose utilisation and lactate production by the intestinepancreas preparation seem to be dependent on the arterial glucose concentration. The proportion of the total glucose infused that was recovered in portal vein as glucose was increased, and the proportion of the total glucose infused that accounts for the lactate pro- duced was reduced when the glucose concentration was increased in the perfusate. An interesting suggestion emerges from these results; despite the different proportions in the portal values of glucose and lactate found at the three arterial glucose concentrations, the percentage of the total carbon atoms from infused glucose recovered in the portal vein remained constant.

\section{Absorption and metabolism of intraluminally supplied glucose}

The intraluminal administration of glucose (1 or $4 \mathrm{~g} / \mathrm{kg}$ body weight) or sucrose ( $4 \mathrm{~g} / \mathrm{kg}$ body weight) resulted in a significant increase in the portal levels of -glucose. The lactate measured in porta was only moderately increased with respect to values measured in the absence of an intraluminal glucose load. These data agree with other in vivo studies in rats [11] and in dogs $[7,13]$ and in rat jejunal segment perfused in vivo $[3,5]$ which have reported that there is little net conversion of glucose into lactate during absorption from the intestine; but they are in sharp contrast with data reported using in vitro perfusion of isolated rat jejunal segment $[2,8,9,12]$ and with in vivo studies carried out in rats with portocaval shunt [4] showing that a considerable proportion of luminal glucose is translocated to the vascular circuit as lactate. Some of these discrepancies could be accounted for by the differences in the arterial and luminal glucose concentration used as suggested by Nicholls et al. [8].

The functional integrity of the epithelial cells seems to be preserved in our preparation as it is suggested by both the time-course of glucose translocation and the low free-glucose content of intestine measured after intraluminal administration of sucrose.

Our results show that translocation of glucose from the lumen to the vascular circuit of the perfused preparations was reduced when the glucose concentration was increased in the perfusion medium. So, the net entry of glucose from the lumen to the blood was apparently increased under hypoglycaemic and reduced under hyperglycaemic conditions. This reduction in the translocation of glucose from the lumen to the blood could be partially dependent on an increase in the metabolism of absorbed glucose. The metabolic fate of this glucose remains to be established. As reported by Windmueller et al. [3], glucose could also be metabolised in rat intesteine to alanine and $\mathrm{CO}_{2}$; and there is also a substantial incorporation of ${ }^{14} \mathrm{C}$-glucose into glycogen, protein and lipid of intestine.

The absence of a clear effect of acute hyperglycaemia on glucose absorption agrees with that previously reported [19, 20], showing that hyperglycaemia generates an increase of the intestinal sugar transport as in experimental diabetes, but the high blood sugar has to be maintained for $4 \mathrm{~h}$ before the intestinal effect appears. 


\section{Insulin secretion}

The preparation showed an adequate insulin release significantly $(p<0.01)$ when increasing the arterial glucose concentration. An increase in insulin secretion was not observed even when a high glucose load $(4 \mathrm{~g} / \mathrm{kg}$ body weight) was supplied intraluminally. These data suggest that, in the rat, there is no direct vascular connection (porta system) between intestine and endocrine pancreas.

\section{Conclusion}

The presented data suggest that, in addition to their endocrine secretory activity, the functional unit intestine-pancreas may play an important role in glucose homeostasis by elaborating the adequate mixture of glucose and lactate that must reach the liver under various metabolic conditions. When increasing the arterial glucose concentration, the capacity of the intestine to metabolise arterially or luminally supplied glucose allows delivery of the maximal effective glucose to the portal blood, whether as glucose itself or as lactate for use by the liver.

Acknowledgment. The authors would like to acknowledge the collaboration of Mr. A. Ali with the English test, and the technical assistance of Mr. E. Fonseca, Miss F. Ropero and Miss A. Llorens. The authors are grateful to Prof. P. Lefebvre, University of Liege, Belgium, by helpful suggestions in the preparation of this manuscript, and to Prof. M. Palacin, University of Barcelona, Spain for helpful discussions of results. This work was supported by a grant from the Comision Asesora de Investigacion Cientifica y Tecnica of Spain (CAICYT PR84-1177).

\section{References}

1. Leese HJ, Bronk JR (1975) Lactate formation by rat small intestine in vitro. Arch Biochim Biophys 404: 40-48

2. Hanson PJ, Parsons DS (1978) Factors affecting the utilization of ketone bodies and other substrates by rat jejunum: effects of fasting and of diabetes. J Physiol 278: 55-67

3. Windmueller HG, Spaeth AE (1978) Identification of ketone bodies and glutamine as the major respiratory fuel in vivo for postabsortive rat small intestine. J Biol Chem 253: 69-76

4. Shapiro A, Shapiro B (1979) Role of the liver in intestinal glucose absorption. Biochim Biophys Acta 586: 123-127

5. Windmueller HG, Spaeth AE (1980) Respiratory fuels and ni- trogen metabolism in vivo in small intestine of fed rats. Quantitative importance of glutamine, glutamate and aspartate. J Biol Chem 255: 107-112

6. Porteous JW (1980) Glutamate, glutamine, aspartate, asparagine, glucose and ketone-bodies metabolism in chick intestinal brushborder cells. Biochem J 188: 619-632

7. Abumrad NN, Cherrington AD, Williams PS, Lacy WW, Rabin D (1982) Absorption and disposition of a glucose load in the conscious dog. Am J Physiol 242: E398-E406

8. Nicholls TJ, Leese HJ, Bronk JR (1983) Transport and metabolism of glucose by rat small intestine. Biochem J 212: 183-187

9. Kellett GL, Jamal A, Robertson JP, Wollen N (1984) The acute regulation of glucose absorption, transport an metabolism in rat small intestine by insulin in vivo. Biochem J 219: 1027 1035

10. Haeckel R, Terlutter H, Schumann G, Dellerich M (1984) Hydrazonotropionic acids, a new class of hypoglycemic substrates, 3. Inhibition of jejunal glucose uptake in the rat and guinea pig. Horm Metabol Res 16: 423-427

11. Niewoehner CB, Gilboe DP, Nuttall FQ (1984) Metabolic effects of oral glucose in the liver of fasted rats. Am J Physiol 246: E89-E94

12. Mallet RJ, Kelleher JK, Jackson MJ (1986) Substrates metabolism of isolated jejunal epithelium conservation of three-carbon units. Am J Physiol 250: C191-C198

13. Kuyumjian J, Kalant N (1986) Absorption of an oral glucose load in the dog. Horm Metabol Res 18: 587-589

14. Creutzfeldt W (1979) The incretin concept today. Diabetologia 16: $75-85$

15. Levin SR, Pehlevanian MZ, Lavee AE, Adachi RI (1979) Secretion of an insulinotropic factors from isolated, perfused rat intestine. Am J Physiol 5: E710-E720

16. Campillo JE, Luyckx AS, Torres MD, Lefebvre PJ (1979) Effect of oleic and on insulin secretion by the isolated perfused rat pancreas. Diabetologia 16: 267-273

17. Richterich R, Colombo JP (1983) Piruvato y lactato. In: Richterich R, Colombo JP (eds) Quimica clinica. Teoria, practica e interpretacion. Salvat, Barcelona, pp 292-297

18. Bergmeyer UH (1974) Determination with glucose oxidase and peroxidase. Methods of enzymatic analysis. Academic Press, New York, pp 1025-1213

19. Jamal A, Kellet GL (1983) Regulation of mucosal phospho-fructoquinase in the small intestine of the streptozotocin-diabetic rat. Diabetologia 25: 355-359

20. Csaky TZ, Fischer E (1981) Intestinal sugar transport in experimental diabetes. Diabetes 30: 568-574

Received: 13 July 1988

and in revised form: 5 October 1988

Dr. M.A. Tormo

Department of Physiology

Faculty of Medicine

Avda. de Elvas $s / n$

Badajoz

Spain 